\title{
A metrópole de São Paulo no contexto da urbanização contemporânea
}

\author{
ANA FANI ALESSANDRI CARLOS
}

$\mathrm{N}$ ESTE TEXTO, que tem a pretensão de ser bastante sintético, tecerei algumas considerações sobre a metrópole de São Paulo nos dias de hoje, especialmente no que diz respeito ao momento atual do processo de urbanização, em que ocorre a acentuação da concentração dos setores econômicos de ponta, como consequência de sua inserção no mercado global, momento caracterizado pela passagem da hegemonia do capital industrial para o capital financeiro. Com isso quero dizer que há um movimento de diminuição dos estabelecimentos industriais - e, portanto, de desconcentração industrial - com centralização do capital, isto é, as indústrias se deslocam para outras áreas (muitas delas dentro do próprio Estado de São Paulo), mas mantêm na metrópole suas sedes.

Esse fenômeno é tratado por muitos como desconcentração produtiva. Os dados do Anuário Exame (2001), referente às 500 maiores empresas no Brasil, nos ajudam a detectar dois comportamentos opostos em relação ao movimento dos estabelecimentos industriais na metrópole: enquanto o número de empresas brasileiras concentradas em São Paulo diminuiu, no período 1990-2000, de 141 para 76, o número de empresas estrangeiras aumentou de 89 para 130, no mesmo período. Ainda mais significativa é a informação sobre o faturamento em vendas dessas empresas, uma vez que em ambos os casos o número é ascendente. As empresas brasileiras apresentam aumento de US\$ 32,4 para US $\$ 37,7$ bilhões em seu faturamento, enquanto as estrangeiras passaram de US\$ 35,6 para US\$ 91,3 bilhões, um aumento substantivo. Por sua vez, as mudanças no setor econômico apontam de forma inequívoca a expansão do setor de serviços (pela prestação dos mais variados serviços) com crescimento acentuado do setor bancário.

Do ponto de vista da centralização do dinheiro, potencialmente capital, os dados mostram que se concentram em São Paulo 19 das 30 instituições financeiras do país, bem como 49 das 100 sedes referentes às maiores empresas privadas brasileiras. Localizam-se também em São Paulo as sedes de 104 dos 177 bancos que atuam no Brasil (representando 59\% do total). No que se refere aos lucros do setor bancário, no ano de 2000 permaneceram em São Paulo 87\% dos lucros gerados em todo país.

Esse movimento orienta a reflexão em direção à busca dos conteúdos do processo de urbanização metropolitana em seu contexto mundial, posto que 
os processos contemporâneos se realizam a partir da integração-desintegração dos espaços em redes mundiais como necessidade e produto da realização da reprodução capitalista num contexto de alta competitividade e fluidez do capital financeiro. Desse modo, o processo de urbanização metropolitana revela a produção de um "novo espaço", isso porque o capitalismo se expandiu e, ao se realizar, tomou o mundo. Esse é o momento da redefinição da metrópole, de sua explosão, da extensão das periferias, da reprodução do espaço num outro patamar em razão dos novos conteúdos do estágio globalizado da economia das relações e dos graus de dependência das áreas entre si.

Na metrópole de São Paulo, o que aparece aos olhos do observador como diferenciações gritantes no plano da paisagem revela, na realidade, os espaçostempos da contradição entre os espaços integrados à economia global e as imensas periferias subordinadas e em fase de desintegração. Isso significa, portanto, que é necessário pensar o processo de urbanização em seus conteúdos mais profundos, o que é muito diferente de associá-lo ao simples comportamento populacional. Pensar os processos que são constitutivos da urbanização, para além da ideia de um crescimento populacional, sem, todavia, desconsiderá-lo, envolve, em primeiro lugar, localizar esse crescimento, que no caso brasileiro se dá principalmente nas periferias metropolitanas, num ritmo muito maior do que nos países do centro do capitalismo.

No Rio de Janeiro e em São Paulo - que são as duas metrópoles brasileiras mais importantes -, podemos afirmar que, do ponto de vista da morfologia, o processo de urbanização se realiza, efetivamente, com a expansão da mancha urbana pela integração de áreas rurais. Tal lógica espacial tem seu sentido no modo pelo qual o Brasil se insere no contexto mundial, e refiro-me aqui ao período inicial da industrialização. Com isso quero dizer que para entender o contexto e as transformações da cidade de São Paulo, bem como seu ritmo de crescimento, é preciso entender a urbanização como consequência de um processo de industrialização "dependente" - ou seja, relativa ao lugar que o Brasil ocupa na divisão internacional do trabalho como exportador de produtos agrícolas e importador de produtos manufaturados -, fundada em altas taxas de exploração da força de trabalho (baixos salários), e "poupadora de mão de obra"; isto é, a industrialização, ao se realizar, deixou à margem do setor produtivo uma "quantidade significativa de força de trabalho" para além do contingente de "exército industrial de reserva" que só pôde sobreviver mediante o desenvolvimento de uma economia chamada de informal.

Trata-se de um processo no qual a urbanização se faz como explosão da cidade, extensão da mancha urbana abrigando a classe trabalhadora em imensas periferias sem infraestrutura, por isso mesmo, destino dessa massa de trabalhadores, posto que o pouco trabalho agregado na terra permitiu sua venda a baixo custo se comparado às áreas centrais da metrópole e possibilitou sua ocupação por aqueles que não podiam pagar por moradias "dignas" em áreas dotadas 
de infraestrutura urbana e, portanto, mais valorizadas. Assim, o modo como o processo de industrialização se realizou gerou uma urbanização profundamente desigual, criando separações entre o centro e a periferia como particularidade da metrópole em constituição. Com isso localizou uma massa expressiva de trabalhadores em áreas sem equipamento e moradias precárias.

Um industrialização dependente, com altas taxas de exploração do trabalho e grande número de desempregados, revelará os conteúdos dos processos constitutivos da periferia. Portanto, o modo como se processa historicamente a urbanização vai revelar que o número de desempregados tende a se agravar posto que o setor terciário não consegue mais absorver, no número desejado, uma população que está desempregada ou à qual se soma uma população que está sendo expulsa do setor industrial em razão da extinção de empregos. Há, nesse sentido, uma articulação dialética entre o setor informal da economia, que nasceu junto com o processo de industrialização dependente (como de resto na América Latina) como solução de sobrevivência de uma classe não absorvida pela indústria nascente, e o novo desempregado.

Decorre daí o fato de que podemos distinguir dois momentos importantes do processo de urbanização da metrópole de São Paulo: a urbanização imediatamente, decorrente do processo de industrialização (processo marcado pela acumulação do capital industrial a partir da acumulação proveniente da agricultura cafeeira, produzindo as grandes periferias a partir da implosão da cidade) e o momento em que o processo de urbanização tem por conteúdo a realização do capital financeiro numa sociedade de consumo, o que permite a ampliação desse processo.

Atualmente, o movimento de passagem da hegemonia do capital industrial para o capital financeiro não que dizer, evidentemente, que a metrópole se desindustrializa, pois o que constatamos é que o processo de desconcentração do setor produtivo das empresas se faz com uma centralização das sedes das empresas em São Paulo. O que há de novo nesse processo é o fato de que o setor financeiro vai se realizar por meio do espaço, isto é, produzindo o espaço, uma vez que o capital tende a migrar de um setor ao outro da economia, e quando isso ocorre, uma nova infraestrutura se torna necessária como condição e meio para que tal processo se realize.

Isso quer dizer que essa centralização financeira vai apontar um fenômeno importante: o capital financeiro se realiza hoje por meio da produção do espaço como exigência da acumulação continuada do capital, sob novas modalidades articuladas ao plano do mundial, constituindo em São Paulo um eixo financeiro empresarial que se estende desde o centro da metrópole em direção ao sudoeste, ocupando áreas antigas de industrialização.

Nesse movimento, uma articulação profunda entre o Estado e os setores econômicos se revela por intermédio de políticas urbanas que direcionam o orçamento público para a construção de uma infraestrutura necessária para 
que esse processo econômico se realize sem sobressaltos. Como consequência, ratifica-se o aprofundamento do processo desigual que se encontra na gênese da história do país.

Em São Paulo, neste momento, o capital vai se reproduzir a partir de três setores dinâmicos da economia - com forte consequência sobre o processo de produção do espaço cuja lógica se articula à economia global.

O primeiro deles é o capital financeiro, e, nessa dimensão, assistimos ao fato de que, para continuar se reproduzindo, o capital o faz por meio da compra da terra urbana (que é o que vai se constituir no eixo empresarial e comercial), em que vamos encontrar as sedes das empresas. Significa, portanto, que o capital sobrante do processo industrial vai ser aplicado no setor imobiliário, com a construção de edifícios inteligentes voltados para o setor de aluguel no qual se abrigarão os novos setores econômicos.

Os termos de reprodução da sociedade no momento se elucidam na produção de um espaço mundializado como realização do capitalismo - no sentido em que o capitalismo necessita superar os momentos de crise da acumulação. Nesse caso, sua reprodução se realiza em direção às novas produções, revelando também um novo papel para o espaço, o que indica o movimento que vai do espaço como condição e meio do processo de reprodução econômica ao momento em que, aliado a esse processo, o espaço, ele próprio, é o elemento da reprodução graças à mudança do papel do solo urbano na economia. Por meio de novas estratégias, como a criação dos fundos de investimentos imobiliários e a produção dos imóveis de escritórios visando ao mercado de locação, o solo urbano deixa de ser elemento de fixidez do investimento e passa a permitir a reprodução do capital financeiro por meio da produção de edifícios de escritórios voltados à realização dos setores modernos da "nova economia" que se instala na metrópole.

Por sua vez, por meio dos fundos imobiliários e do mercado financeiro, forma-se uma nova articulação entre os setores industrial e imobiliário, construindo edifícios que não serão destinados à venda. Na realidade, esse capital industrial/ financeiro vai produzir edifícios corporativos direcionados ao novo setor da economia num momento em que as transformações do processo produtivo, ante as novas condições de competitividade do mercado, tornam impossível a imobilização do capital na compra do imóvel, pois isso oneraria os custos de produção.

Assim, o capital não se imobiliza na compra do imóvel, sendo preferível alugá-lo, e é nesse movimento que o capital ganha mobilidade. Nos anos 1990, a terra urbana muda de sentido para o capital, deixando de ser um lugar de fixidez para ser o lugar por meio do qual esse vai se realizar, apoiando-se no redirecionamento das políticas urbanas na direção de construir o ambiente necessário para que esse capital possa se realizar, transformando a metrópole.

Do ponto de vista da morfologia urbana, a construção material e objetiva desse espaço faz-se em detrimento dos setores da população residente nele. 


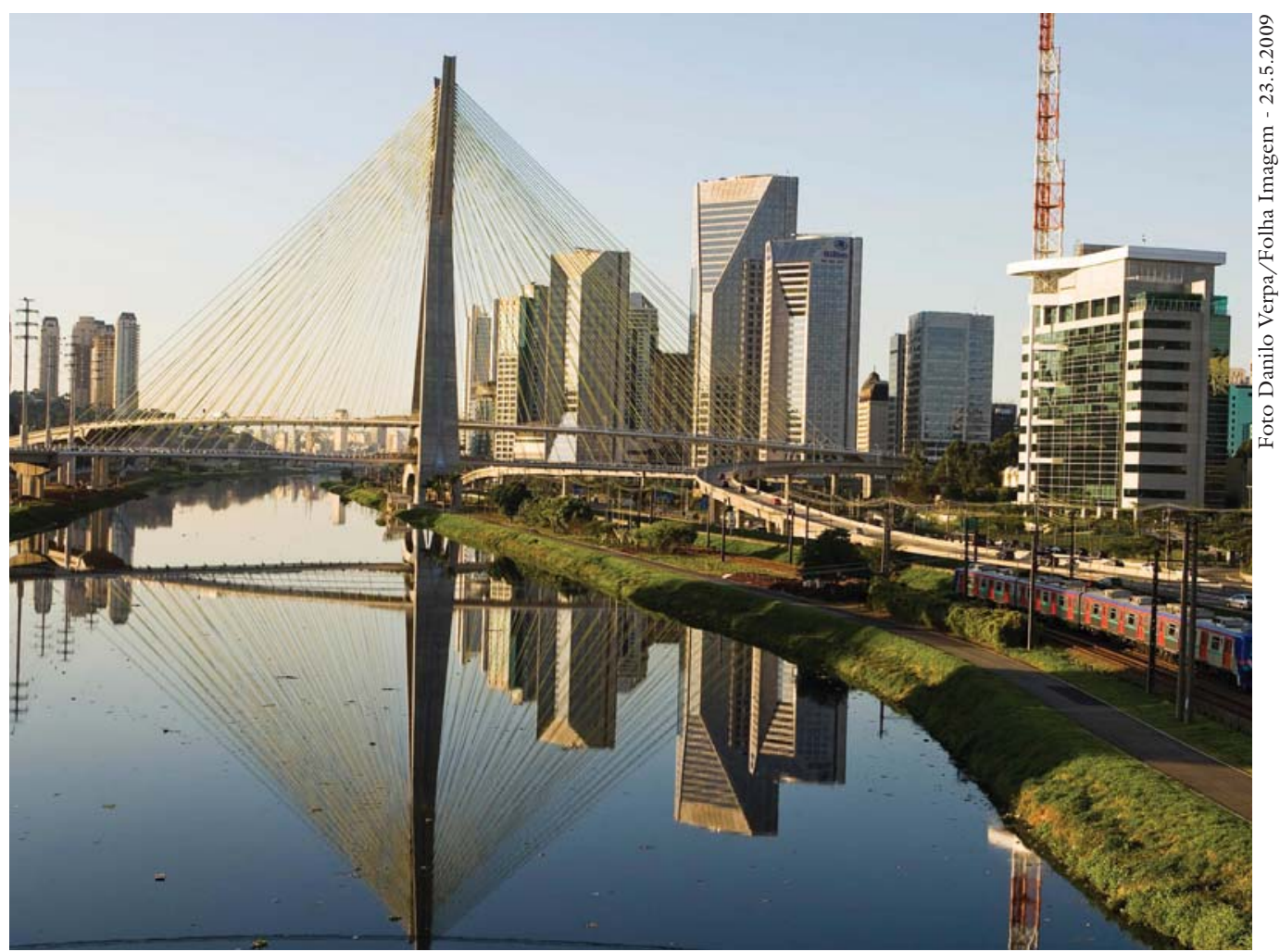

A ponte estaiada Octavio Frias de Oliveira, sobre o Rio Pinheiro, em São Paulo (SP).

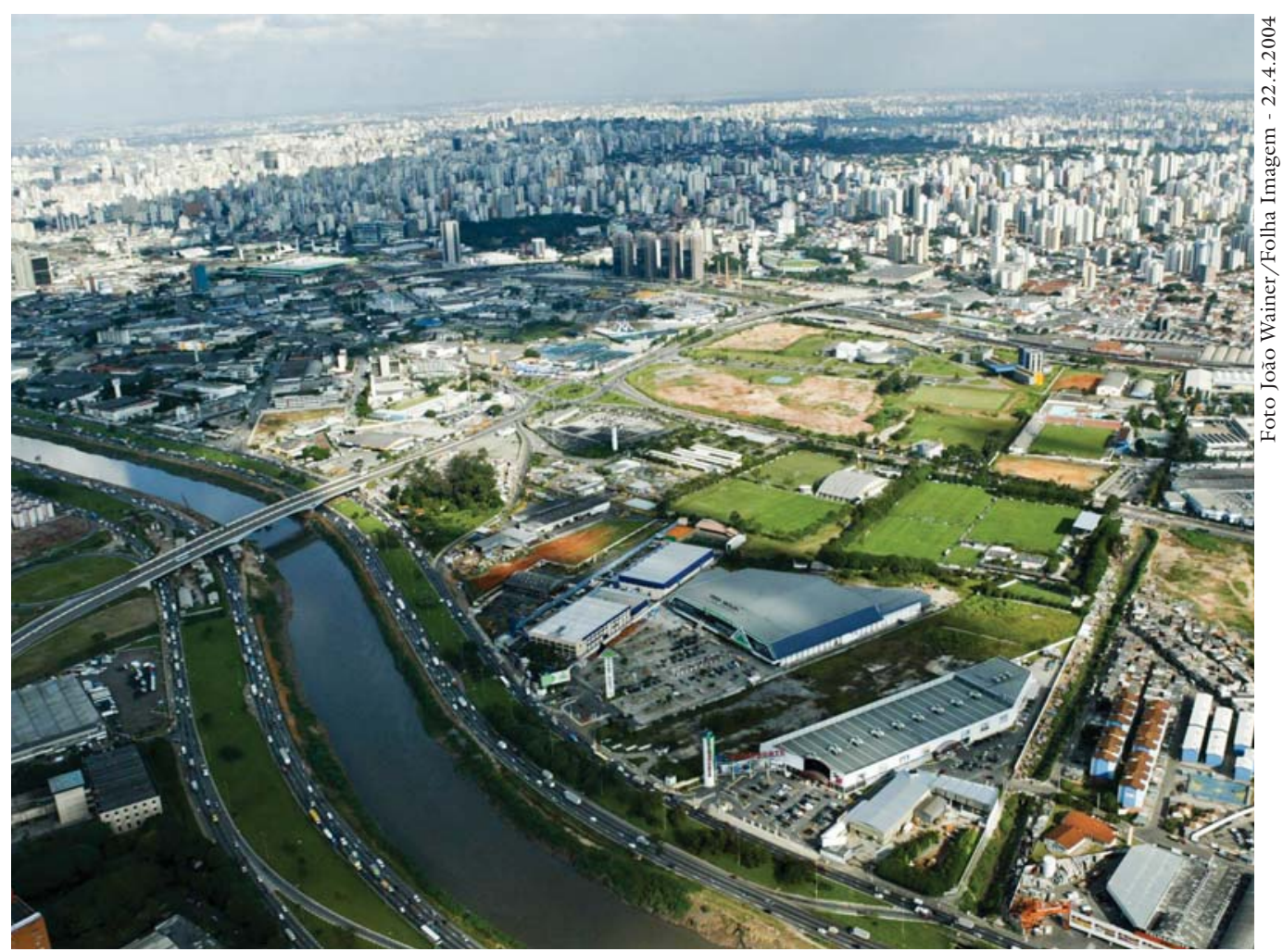

Vista aérea da região Oeste da cidade de São Paulo (SP). 
Dessa forma, numa metrópole superedificada como São Paulo, as mudanças que levarão à construção do eixo empresarial-comercial não se limitarão apenas às antigas áreas industriais, mas chegarão às áreas residenciais, cabendo ao Estado decretar a "área como aquela de uso público", o que permitirá o processo de desapropriação, expulsando a população que aí mora. A primeira decorrência disso é a expulsão da população que mora na área de construção dos novos edifícios (área diretamente desapropriada); a segunda é a expulsão da população (nas áreas contíguas) que paga aluguel, pois o processo de valorização que acompanha a transformação da área os faz aumentar. Finalmente, existem aqueles que preferem vender as casas para a construção de novos edifícios, pois a explosão do bairro lhes é insuportável e a valorização dos terrenos age como incentivo ao deslocamento. Mas, antes de quaisquer arranjos, expulsa-se a favela em direção à periferia, o mais distante possível.

Esse processo se realiza, portanto, por meio de uma aliança entre o governo do município e os setores econômicos envolvidos de modo a integrar essa área ao mercado global.

O segundo setor de realização do capital no mundo moderno - como momento de sua reprodução - refere-se à atividade turística. São Paulo é, sintomaticamente, o lugar no Brasil que recebe o maior número de turistas - trata-se, todavia, de uma atividade associada às atividades econômicas modernas, o que se convencionou chamar de "turismo de negócios". Isso quer dizer que essa atividade acaba também permitindo a construção de uma infraestrutura hoteleira localizada na área de expansão do centro moderno da metrópole. Nessa área, encontram-se, ao lado dos escritórios de alta tecnologias (que são chamados de escritórios AA), os novos hotéis que atendem preferencialmente as pessoas que vêm aqui a trabalho e não a passeio.

A produção dessa região de edifícios e hotéis na metrópole se insere, assim, numa nova lógica de reprodução do capital financeiro que agora tende a englobar o solo urbano como possibilidade de sua reprodução. Desse modo, o movimento da transformação do dinheiro em capital vai agora percorrer novos caminhos, revelando os novos conteúdos para o processo de urbanização atual.

O turismo é um novo setor importante da economia (tanto quanto o capital industrial), realizando-se por meio do espaço e produzindo e consumindo um determinado tipo de lugar na metrópole. Estamos assistindo aqui a um movimento do uso dos espaços, que vai do consumo no espaço para o consumo do espaço. Ou seja, por meio das atividades econômicas voltadas ao turismo, produzem-se espaços para serem consumidos, e no caso da cidade de São Paulo, referindo-se a um turismo de negócio, trata-se de um conjunto de atividades que se realiza por meio dos "negócios" aqui acumulados pela concentração dos setores de ponta da economia. Não é coincidência que os hotéis se instalem na área do eixo empresarial-comercial da metrópole paulistana, enquanto no Rio de Janeiro uma parte significativa do fluxo de turistas tem por objetivo o consu- 
mo do espaço como consumo de suas particularidades materiais. Logo há uma diferença no modo como a atividade turística se realiza produzindo um espaço em São Paulo e a atividade turística que se realiza no Rio de Janeiro como uma produção turística ligada à transformação do sentido do espaço como do uso produtivo, voltado à reprodução ampliada do capital como momento de reprodução dos lugares.

Finalmente, a reprodução do capital no mundo moderno se realiza num terceiro setor econômico, que é o do narcotráfico, que, por sua vez, só se realiza produzindo o seu próprio espaço, como normatização estrita do uso e dos acessos. A ilegalidade do narcotráfico faz que o domínio sobre determinado lugar passe a ser central para que essa atividade possa se realizar, e convém não esquecer que, se o narcotráfico fosse extinto hoje, o mercado financeiro entraria em colapso.

Do ponto de vista da reprodução econômica do capital, os três setores justapostos permitem altamente sua realização - setores esses integrados ao mercado, sob as estratégias da globalização. Esses três momentos, por sua vez, revelam os conteúdos da urbanização contemporânea em que o espaço aparece como condição necessária ao processo de reprodução do capital, na direção apontada por Harvey - e enunciada também por Henri Lefebvre nos anos 1980 - que é a de que o processo de reprodução do capital a partir dos anos 1980 realiza-se produzindo um "novo espaço" - o que quer dizer que o capital só pode se realizar por meio de uma nova estratégia que faz do espaço um elemento produtivo -, momento central a partir do qual a reprodução do capital vai se realizar superando as crises de acumulação. Todavia, para Harvey, essa possibilidade estaria na base da constituição do que chama de "novo imperialismo", pois, segundo sua teoria, a articulação entre os espaços articulados às necessidades de expansão dos mercados englobaria espaços em que ainda se realizaria uma acumulação primitiva. $O$ raciocínio deste texto concorda com o ponto de vista de que o atual processo de reprodução da sociedade passa, necessariamente, pela reprodução do espaço nos termos propostos por Harvey, porém há ainda um processo de reprodução continuada do capital que se realiza nos espaços metropolitanos configurando novas morfologias articuladas sob novas estratégias, o que sinaliza um deslocamento do fenômeno. Assim, trata-se, também, de pensar na reprodução da metrópole como espaço-tempo necessário à reprodução do capital, o que implicaria a consideração de um duplo movimento: no plano internacional constituindo-se num novo conteúdo para a análise do imperialismo, tal qual apontado por Harvey, e aquele que se refere à reprodução no plano da metrópole, esclarecendo os novos conteúdos do processo de urbanização sob novas estratégias, agora associadas a uma nova relação estado/espaço.

Dessa forma se constrói uma hipótese: a reprodução do espaço urbano da metrópole sinaliza o momento em que o capital financeiro se realiza também por meio da produção de "um novo espaço" sob a forma de "produto imobiliário" 
voltado ao mercado de locação (fundamentalmente no que se refere aos edifícios corporativos de escritórios, rede hoteleira e flats) numa estratégia que associa várias frações do capital a partir do atendimento do setor de serviços modernos. Nesse sentido, estabelece-se um movimento de passagem da predominância/ presença do capital industrial produtor de mercadorias destinada ao consumo individual (ou produtivo) à preponderância do capital financeiro que produz o espaço como mercadoria como condição de sua realização - aqui o espaço torna-se produtivo. Todavia, convém esclarecer que o espaço-mercadoria, tornado "produto imobiliário", se transforma numa mercadoria substancialmente diferente daquela produzida até então, pois trata-se, agora, de uma mercadoria voltada essencialmente ao "consumo produtivo", isto é, entendido como momento da reprodução do capital financeiro em articulação estreita com o capital industrial (basicamente o setor de construção civil) que, pela mediação do setor imobiliário, transforma o investimento produtivo no espaço sobrepondo-se ao investimento improdutivo e regulando a repartição das atividades e usos.

O momento atual sinaliza, portanto, uma transformação no modo como o capital financeiro se realiza na metrópole hoje: a passagem da aplicação do dinheiro do setor produtivo industrial ao setor imobiliário, associado ao conjunto das indústrias voltadas à construção civil. Assim, a mercadoria-espaço mudou de sentido com a mudança da orientação das aplicações financeiras, que produz o espaço como "produto imobiliário". Por sua vez, esse processo requer uma outra relação Estado/espaço - pois só ele é capaz de atuar no espaço da cidade mediante políticas que criam a infraestrutura necessária para a realização desse "novo ciclo econômico", além da redefinição da lei de zoneamento, e da desapropriação das áreas necessárias para a construção de um "novo espaço". Nesse sentido, a produção do espaço se realiza num outro patamar: o espaço como momento significativo e preferencial da realização do capital financeiro, como condição e produto desse processo.

Assim, o processo de reprodução do espaço da metrópole, no contexto mais amplo do processo de urbanização, a) marca a desconcentração do setor produtivo e a acentuação da centralização do capital na metrópole, bem como cria um outro conteúdo para o setor de serviços (basicamente o que se desenvolve é o financeiro e de serviços sofisticados e, com ele, uma série de outras atividades de apoio como aqueles de informática, serviços de telecomunicações, consultorias); b) sinaliza um novo momento do processo produtivo no qual novos ramos da economia ganham importância - trata-se, particularmente, do que se chama de "nova economia", contemplando o setor do turismo e lazer, bem como a redefinição de outros setores, como é o caso do comércio e serviços para atender ao crescimento dessas atividades; c) estabelece o movimento de transformação do dinheiro em capital, que percorre agora, preferencialmente, outros caminhos - a criação dos fundos de investimento imobiliários atesta, por exemplo, que o ciclo de realização do capital se desloca para novos setores da 
economia reproduzindo os lugares como condição de sua realização -; d) revela uma nova relação Estado/espaço - que aparece, por exemplo, por meio das políticas públicas que orientam os investimentos em determinados setores e em determinadas áreas da metrópole com a produção de infraestruturas e "reparcelamento" do solo urbano por meio da realização de operações urbanas e da chamada requalificação de áreas - especialmente centrais - mediante a realização de "parcerias" entre a prefeitura e os setores privados que acabam influenciando e orientando essas políticas; e) centraliza o capital financeiro em São Paulo em relação ao resto do território brasileiro; f) redefine a centralidade da metrópole no território nacional; g) efetua o aprofundamento da desigualdade socioespacial, uma vez que, no plano da metrópole, a transformação do espaço em mercadoria, condição da extensão do mundo da mercadoria, entra em conflito com as necessidades de realização da vida urbana. Aqui defronta-se o espaço como valor de uso - como espaço-tempo da reprodução da vida - com aquele do valor de troca - o espaço produtivo - como momento necessário à reprodução do capital no momento de transformação do setor industrial, como setor prioritário de realização da acumulação.

Essa contradição produz outras, mas à que me refiro neste texto é aquela que produz os lugares da metrópole integrados ao capitalismo globalizado e chamados de modernos, e uma vasta área fora da lógica da reprodução imediata do capital financeiro - apesar de ser seu produto imediato -, que estou denominando "desintegrada" em relação à reprodução do capital que aparece como produto, e não como condição de sua realização. A produção desse espaço compõe uma dialética entre a integração e a desintegração dos lugares da metrópole, uma particularidade que é produto da história do modo como o capitalismo se realiza na periferia do sistema.

Tal processo de desintegração que aparece na mancha urbana refere-se ao fato de que o que é histórico no Brasil, na sua condição de país periférico, é produzir uma massa de trabalhadores ou uma massa de população - força de trabalho em potencial - que não tem acesso ao mercado de trabalho. O setor integrado da economia mundial não consegue gerar um setor terciário capaz de englobar essa população, daí decorre que o setor informal se desenvolve com bastante força, aprofundando a desigualdade. A essa população resta se localizar na periferia da mancha urbana. No caso do Rio de Janeiro, isso acontece em seus interstícios, ou seja, as favelas sobem os morros; e no caso de São Paulo, surgem os cortiços no centro e em áreas de favelas pela mancha urbana, mas, à medida que essa se adensa e se valoriza, a massa de trabalhadores informais é expulsa em direção à periferia.

No fundamento do acesso à metrópole como uso, encontra-se a propriedade privada da riqueza, fundamentalmente a do solo urbano. O processo de produção da cidade capitalista se faz tornando-a mercadoria, que, fragmentada pela existência da propriedade privada da terra, é vendida em pedaços no merca- 
do imobiliário. Produzida sob a lógica internacional atual, a cidade inteira pode adquirir esse sentido e ser vendida em sua totalidade como mercadoria. É o que demonstra o novo mercado das "cidades globais" vendidas no mercado de turismo ou de investimento seguro para reproduzir o capital sobrante na economia em busca de novas possibilidades de geração de lucro.

As áreas não integradas ao setor globalizado da economia que formam grandes periferias são os lugares onde a população pode morar, o que lhe sobra até o novo momento de valorização do espaço que vai expulsá-la para mais longe. Mas a periferia é complexa, e não é só o lugar do pobre, o que significa que esse sentido sociológico de periferia está superado, não encontrando respaldo na realidade, pois: a) em São Paulo, a periferia recebe as indústrias, posto que as áreas valorizadas pelo processo de extensão do espaço urbano valorizam também a terra e expulsam as indústrias para áreas cujo preço do metro quadrado de terreno seja menor, de modo a não onerar os custos de produção; b) nela também se encontram os condomínios de luxo que são construídos como estratégia de reprodução do setor imobiliário, uma vez que a metrópole superedificada, com escassez de terrenos incorporáveis para a construção, exige a busca de novas soluções. O setor de construção dos condomínios é produto de uma lógica imobiliária que vende o espaço da periferia para a classe média, que, todavia, precisa ser convencida dessa nova "necessidade de habitar". É dentro dessa lógica que se produzem as novas estratégias de marketing assentadas na ideia de "qualidade de vida", que contempla um conjunto de itens todos eles voltados à necessidade de ampliar a base social sob a qual se desenvolve a sociedade de consumo - agora como consumo também do espaço. Dessa faz parte a necessidade de segurança, da proximidade de pessoas de mesma renda, da vida junto à natureza, onde o verde aparece como elemento importante nesse processo. Com isso assistimos ao fato de que o processo de produção transforma a natureza em recurso natural, e, nessa condição, essa natureza passou a ser mercadoria; e a busca do lucro imediato fez que ela fosse degradada, uma vez que o processo teve de ser rapidamente realizado. Nessa condição de degradação, a natureza se transforma em raridade, e a crise ecológica é um produto incontestável do modo como o capital se reproduziu, especialmente nos países periféricos. Na condição de raridade essa natureza sobrante, ou simbolicamente sobrante - trata-se na realidade da natureza reproduzida socialmente -, é vendida no mercado imobiliário para justificar a construção dos conjuntos habitacionais para a classe de renda alta que, caso contrário, não se deslocaria para longe de seus empregos, lugares de lazer etc.; c) a massa de desempregados, subempregados, empregados mal pagos, em suma, uma população de baixíssima renda que não pode morar nesses condomínios, vai morar nas áreas menos valorizadas também na periferia, às vezes muito próxima desses, mas em áreas com menos serviços e infraestrutura que são elementos valorizadores do espaço, posto que trabalho materializado fundamento do valor do solo urbano. 
Parte dessa parcela da população que mal tem dinheiro para comer vai se localizar exatamente nos lugares onde a propriedade privada da terra não vigora, ocupando áreas do Estado; portanto, áreas públicas, muitas delas localizadas em áreas de proteção de mananciais, produzindo o que alguns pesquisadores denominam "cidade informal", e outros, ainda, "cidade ilegal". Assim, ocupamse áreas de mata original, de florestas, ou as áreas de morros. Em São Paulo, a mancha urbana que se expande no sentido leste-oeste marca as barreiras naturais - Serra da Cantareira ao norte, lagos e represas ao sul -, que aos poucos vão cedendo lugar à construção de habitações precárias.

Do ponto de vista da ação do governo (por sua intervenção direta ou pelas das políticas urbanas), as verbas públicas são, preferencialmente, alocadas nos lugares capazes de viabilizar a reprodução do capital de modo a viabilizar/ fortalecer o papel econômico da metrópole de São Paulo na rede mundial das cidades. Com isso deixa de privilegiar a massa de população pobre que vai ocupar essas áreas que, em tese, não poderiam ser em hipótese alguma ocupadas, uma vez que compõem o "pulmão da cidade" ou o lugar do abastecimento de água. Essa massa de população que vive em condições subumanas, seja no que se refere à habitação, seja quanto à realização das necessidades básicas da vida, é duplamente penalizada no processo, num primeiro momento pela limitação de acesso à riqueza social produzida, e num segundo é tachada de inconsequente, ou sem consciência ecológica por ocupar essas áreas. Com isso, a mancha urbana revela a justaposição morfologia social/morfologia espacial. Portanto, as metrópoles de São Paulo e do Rio de Janeiro revelam uma justaposição entre uma morfologia social e uma morfologia espacial que manifesta a relação entre a renda ou salário do trabalhador e de sua família e o preço do metro quadrado do solo urbano na metrópole.

Essa lógica da reprodução do espaço metropolitano paulistano está no fundamento da degradação da natureza. Trata-se, como afirmamos, de uma produção do espaço urbano definida pela própria lógica do processo de produção da sociedade capitalista em sua especificidade de metrópole de um país periférico como o nosso, historicamente desigual, cuja desigualdade só faz aprofundar. Portanto, a dialética espacial integração/desintegração das diferentes áreas da metrópole ao processo de globalização revela contradições sociais do processo de reprodução do espaço urbano. Esse processo revela de forma potencializada a contradição fundante da produção do espaço urbano entre produção social e apropriação privada - gênese da segregação. Talvez seja o caso de se afirmar que não é a falta de planejamento que está por trás da crise ecológica e do que se convencionou chamar de "caos urbano", mas a própria lógica do planejamento numa sociedade capitalista, dependente, como a brasileira.

Referências bibliográficas

CARLOS, A. F. A. O lugar no/do mundo. São Paulo: Hucitec, 1996. 
CARLOS, A. F. A. Espaço e tempo na metrópole. São Paulo: Contexto, 2001.

. São Paulo: do capital industrial ao capital financeiro. In: CARLOS, A. F. A.; OliveirA, A. U. (Org.) Geografias de São Paulo. São Paulo: Contexto, 2004. v.2. O espaço urbano: novos escritos sobre a cidade. São Paulo: Labur, 2007. Disponível em: <http://www.fflch.usp.br/dg/gesp>. Acesso em: 2 dez. 2007. . A (re)produção do espaço urbano. 2.ed. São Paulo: Edusp, 2008.

HARVEY, D. Los límites del capitalismo y la teoría marxista. Cidade do México: Fondo de Cultura Econômica, 1990. Espaços de esperança. São Paulo: Loyola. 2004. . O novo imperialismo. São Paulo: Loyola, 2004. A produção capitalista do espaço. São Paulo: Annablume, 2005.

LEFEBVRE, H. La survie du capitalisme. Paris: Anthropos, 1973.

MARX, K. Grundrisse, 2. Chapitre du capital. Paris: Anthropos, 1968. El capital. Cidade do México: Siglo Veintiuno, 1984. t.II, v.4.

REVISTA EXAME. Melhores e maiores. São Paulo, n.745, jul. de 2001.

RESUMO - O presente artigo tem por objetivo apontar os principais aspectos da produção do espaço urbano na metrópole de São Paulo, hoje. A tese central repousa na constatação da passagem da hegemonia do capital industrial ao capital financeiro o que exige a construção de um "novo espaço" que compõe o eixo empresarial e comercial de São Paulo, constituindo-se numa extensão da centralidade econômica baseada na relação entre as frações de capital e o Estado.

PALAVRAS-CHAVE: São Paulo, Reestruturação espacial, Setor financeiro, Espaço urbano, Metrópole.

ABSTRACT - This paper attempts to reveal the main aspects of the production of the urban space of São Paulo. Our central hypothesis is that the industrial activity tends to leave the municipality of São Paulo, which has increasingly become a "command center" of the national economy, attracting corporate headquarters and banking services. This has given rise to a spatial restructuring based on the coalition between the real estate sector, the financial sector and the state.

KEYWORDS: São Paulo, Spatial restructuring, Financial sector, Urban space, Metropolis.

Ana Fani Alessandri Carlos é professora titular em Geografia do Departamento de Geografia da Faculdade de Filosofia, Letras e Ciências Humanas, Universidade de São Paulo. @-anafanic@usp.br

Recebido em 18.5.2009 e aceito em 2.6.2009. 